\title{
The Role of Infrastructure Investment Location in China's Western Development
}

\author{
By Xubei Luo
}

\begin{abstract}
Development of the western region is vital to the balanced growth of China. Luo studies the impacts of infrastructure investment that may most efficiently alleviate the burden of geographical remoteness of the West.

Having constructed the "adjusted distance" to approximate the transport cost, which takes into account the effects of real distance and infrastructure development, the author defines the "peripheral degree" to measure the effective remoteness of a province to an economic center. Using panel data for 1979-99 from the Chinese provinces, she shows that geographic attractiveness plays a significant role in a Solow-type growth determination model. Given the invariability of pure geographic position, progress in transportation facilities is essential to reduce the geographic handicap and to encourage the catching-up of the western region.

The author's simulation results show that the central transportation hubs (Hubei, Henan, and Hunan) merit most the infrastructure investments, for they favor the development of many provinces, if regional balanced growth is considered as the prime objective. In particular, improvement in the transportation facilities in central hubs will have greater effects on western development than that in the western region by itself. Improvements in the transportation facilities of the central hubs substantially improves the geographic attractiveness of the western region by reducing the transport cost from the West to the Coast and by promoting the emergence of new economic centers in such hubs, which tends to modify the national economic geographic structure.
\end{abstract}

World Bank Working Paper 3345, June 2004

The Policy Research Working Paper Series disseminates the findings of work in progress to encourage the exchange of ideas about development issues. An objective of the series is to get the findings out quickly, even if the presentations are less than fully polished. The papers carry the names of the authors and should be cited accordingly. The findings, interpretations, and conclusions expressed in this paper are entirely those of the authors. They do not necessarily represent the view of the World Bank, its Executive Directors, or the countries they represent. Policy Research Working Papers are available online at http://econ.worldbank.org.

Xubei Luo

The World Bank

Office of Senior Vice Presidency Dev Econ/Chief Econ (DECVP)

MSN MC4-404

1818 H Street, N.W.

Washington D.C. 20433

Tel: 12024581157

Email:xluo@worldbank.org 


\title{
The Role of Infrastructure Investment Location in China's Western Development
}

\author{
By Xubei Luo*
}

\section{Introduction}

China, with a population of 1.3 billion and a surface of 9.6 million squared kilometers, has achieved great success since the late 1970s. The country's economic size increased more than 6.5 times in 21 years as the Gross Domestic Product (GDP) increased from \$145 billion USD (constant 1995) in 1978 to \$964 billion USD (constant 1995) in 1999. ${ }^{1}$

Despite this great success of the economy as a whole, China has suffered from unbalanced growth among the different provinces: the coastal region is much more developed than the inland area due to more favorable geographic position and economic policies. ${ }^{2}$ In general, the farther away a province is from the coast, the weaker its performance is. In 1999, the GDP per capita of the western provinces was less than half of that of the coastal provinces. Such unbalanced regional growth hinders the further development of the Chinese economy. On one hand, the backwardness of the western region and resulting inequality of incomes across China undermines longer-term growth prospects and social stability; on the other hand, the underdevelopment limits the potential of domestic market enlargement, hindering the possibility of the relocation process of traditional industries from eastern regions to central and western ones.

In addition to the topological and climatic disadvantages, the western provinces experience limited market accessibility due to their geographical remoteness from the domestic economic centers of the coast. We argue that it is the transport cost, which is

\footnotetext{
* The author is indebted to Deepak Bhattasali and Paul Brenton for excellent comments. The author is also grateful to Henri-François Henner and Nong Zhu for fruitful discussion.

${ }^{1}$ Source: World Bank database.

${ }^{2}$ In general, according to the criterion of geographic position, we classify Chinese provinces into three categories: coastal, central, and west. According to the regional classification of the "Statistics of China's Fixed Assets and Investment 1950-1985," the coastal region includes Liaoning, Hebei, Beijing, Tianjin, Shandong, Jiangsu, Shanghai, Zhejiang, Fujian, Guangdong, Hainan; the central region includes Heilongjiang, Jilin, Nei Mongol, Shanxi, Henan, Anhui, Hubei, Hunan, Jiangxi; the western region includes Guangxi, Shaanxi, Gansu, Ningxia, Qinghai, Xinjiang, Chongqing, Sichuan, Yunnan, Guizhou, Xizang. Here, although Guangxi has direct access to sea, it is considered as a western province given its economic backwardness. The central region and the western region are considered as the inland regions. See annex 1 for more details.
} 
conditioned by the real distance and by the infrastructure development level of the itinerary, rather than the distance per se that influences interregional trade volume. We thus construct an indicator "peripheral degree" to measure the geographic attractiveness of a province, namely, its effective remoteness to economic centers. The significant negative role that the remoteness to the economic centers, that is, the peripheral degree, plays on regional growth suggests a pessimistic prognosis for the development of the western provinces. The most efficient way to facilitate the growth of the inland/western provinces is to develop the infrastructure to lower the transport cost and lessen the relative effective remoteness of the western region. In general, for a given distance, the better the infrastructure is, the lower the transport costs are and the better the market accessibility is. Infrastructure development will "shorten" the distance, so that geographic position will play a less important role.

Given current limitations on infrastructure investments, the key question becomes how to efficiently locate infrastructure investment to optimize the effects on regional development. By simulating the influence of a 10 percent increase in transportation network density in each province, we demonstrate that infrastructure investments in transportation hubs in central China have greater effects on western development than those in the western region; the former lowers the effective remoteness of the West to economic centers. On the one hand, the improvement of the transportation facilities in central hubs reduces the transport cost between West and East; on the other hand, the emergence of the central provinces as regional economic centers modifies the geo-economic production structure in favor of lowering the peripheral degree of the West. ${ }^{3}$

This paper is organized as follows: section two emphasizes the unbalanced regional growth and briefly reviews the theoretical models; section three focuses on the construction of the adjusted distance and peripheral degree; section four demonstrates the role of geographic position on regional growth determination; section five simulates the effects of different infrastructure investment location on regional growth; and section six presents our policy suggestions on the development of transportation facility in central transportation hubs.

\section{Background Description and Theoretical Review}

In China, coastal provinces have experienced higher growth rates and better development than have the inland provinces. Accordingly, we consider the coastal provinces

\footnotetext{
${ }^{3}$ See Fujita, Krugman, and Venables (1999).
} 
to be economic centers. Favored by economic policies of opening-up and by advantageous geographical positions, the growth rate of coastal provinces was much higher than that of the inland provinces for the last two decades. This higher growth rate further enlarged the development gap (table 1). ${ }^{4}$

Table 1. Provincial GDP Per Capita and Annual Growth Rate

\begin{tabular}{|c|c|c|c|c|c|c|c|c|}
\hline \multirow{2}{*}{$\begin{array}{l}\text { Provincial } \\
\text { Code }\end{array}$} & \multirow[b]{2}{*}{ Province } & \multicolumn{4}{|c|}{ GDP per capita (yuan 1978) } & \multicolumn{3}{|c|}{$\begin{array}{c}\text { Average annual growth rate } \\
(\%)\end{array}$} \\
\hline & & 1978 & 1985 & 1992 & 1999 & $79-89$ & $90-99$ & $79-99$ \\
\hline \multicolumn{9}{|l|}{$\begin{array}{l}\text { Coastal } \\
\text { Region }\end{array}$} \\
\hline 1 & Beijing & 1249 & 2109 & 3358 & 6222 & 7.01 & 8.35 & 7.65 \\
\hline 2 & Tianjin & 1141 & 1941 & 2714 & 5656 & 6.14 & 9.25 & 7.62 \\
\hline 3 & Hebei & 362 & 586 & 994 & 2239 & 6.99 & 10.53 & 8.68 \\
\hline 6 & Liaoning & 675 & 1107 & 1759 & 3164 & 7.23 & 7.49 & 7.35 \\
\hline 9 & Shanghai & 2484 & 4032 & 6161 & 14065 & 6.16 & 10.57 & 8.26 \\
\hline 10 & Jiangsu & 427 & 872 & 1722 & 4082 & 9.94 & 11.64 & 10.75 \\
\hline 11 & Zhejiang & 330 & 805 & 1529 & 3796 & 10.69 & 12.68 & 11.63 \\
\hline 13 & Fujian & 271 & 567 & 1102 & 2895 & 9.73 & 13.00 & 11.29 \\
\hline 15 & Shandong & 315 & 614 & 1099 & 2614 & 8.67 & 11.62 & 10.08 \\
\hline 19 & Guangdong & 365 & 725 & 1637 & 3600 & 10.06 & 11.83 & 10.90 \\
\hline \multicolumn{9}{|l|}{ Central } \\
\hline 4 & Shanxi & 363 & 637 & 905 & 1611 & 6.70 & 7.53 & 7.10 \\
\hline 5 & Nei Mongol. & 318 & 630 & 964 & 1747 & 8.16 & 8.04 & 8.11 \\
\hline 7 & Jilin & 381 & 668 & 1099 & 2115 & 8.03 & 8.29 & 8.16 \\
\hline 8 & Heilongjiang & 558 & 835 & 1218 & 2102 & 5.62 & 7.07 & 6.31 \\
\hline 12 & Anhui & 242 & 483 & 657 & 1548 & 8.07 & 9.68 & 8.84 \\
\hline 14 & Jiangxi & 273 & 488 & 781 & 1623 & 7.51 & 9.55 & 8.48 \\
\hline 16 & Henan & 231 & 453 & 702 & 1480 & 8.34 & 9.42 & 8.85 \\
\hline 17 & Hubei & 330 & 662 & 973 & 2108 & 8.14 & 9.59 & 8.83 \\
\hline 18 & Hunan & 285 & 463 & 702 & 1363 & 6.38 & 8.65 & 7.46 \\
\hline \multicolumn{9}{|l|}{ Western } \\
\hline Region & & & & & & & & \\
\hline 20 & Guangxi & 223 & 334 & 534 & 1062 & 5.15 & 9.95 & 7.44 \\
\hline 21 & Sichuan & 252 & 475 & 737 & 1361 & 7.73 & 8.36 & 8.03 \\
\hline 22 & Guizhou & 174 & 326 & 472 & 765 & 7.74 & 6.33 & 7.07 \\
\hline 23 & Yunnan & 223 & 395 & 650 & 1141 & 7.88 & 7.64 & 7.77 \\
\hline 24 & Shaanxi & 292 & 500 & 782 & 1415 & 7.81 & 7.20 & 7.52 \\
\hline 25 & Gansu & 346 & 515 & 844 & 1487 & 6.69 & 7.22 & 6.94 \\
\hline 26 & Qinghai & 426 & 627 & 805 & 1355 & 4.81 & 6.29 & 5.51 \\
\hline 27 & Ningxia & 366 & 618 & 885 & 1531 & 7.07 & 6.54 & 6.82 \\
\hline 28 & Xinjiang & 317 & 621 & 1098 & 1769 & 8.70 & 7.63 & 8.19 \\
\hline
\end{tabular}

Source: China Statistical Yearbook (various editions) and author's calculations. The data of Chongqing are included in Sichuan for better coherence. We do not include Hainan, which is an island without direct road/railway connection with the continent, and Xizang because of their special characteristics.

\footnotetext{
${ }^{4}$ See Démurger and others (2001) for a detailed description of Chinese regional development history - favored by the geographically targeted Region Development Plan initiated under Deng Xiaoping and the advantageous endowment, coastal provinces developed much better than the inland ones following reforms.
} 
Taking out the three city provinces of Beijing, Tianjin, and Shanghai, figure 1 shows the enlarging regional development gap: at the end of 1990s, all coastal provinces were more developed than the inland ones. ${ }^{5}$ The curves parallel to the axis "year" show the better performance of the coastal provinces during the last two decades with the steeper slopes; those parallel to the axis "code" confirm the backwardness of the inland provinces, in particular the western ones, with lower levels of GDP per capita in each corresponding year.

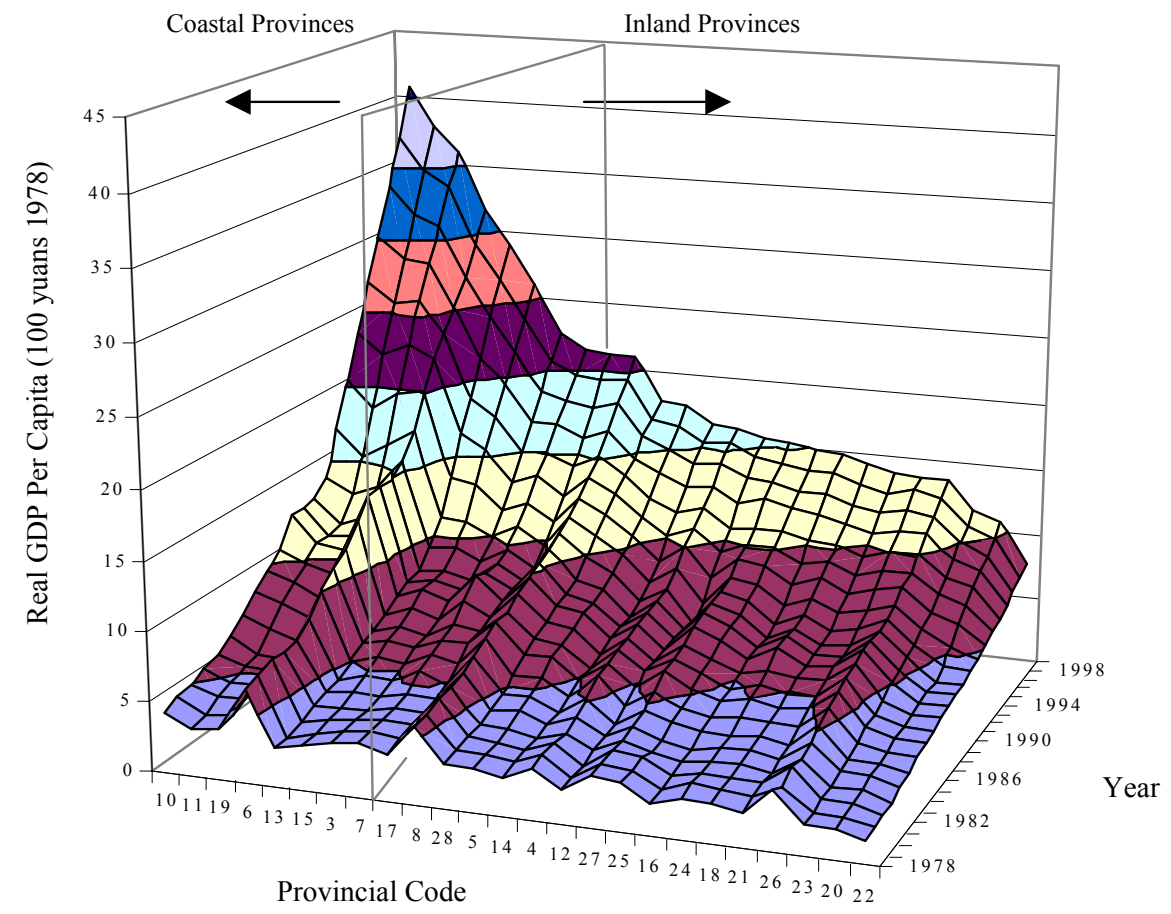

Figure 1. Enlarging Development Gap between Coastal Provinces (except Beijing, Tianjin, and Shanghai) and Inland Provinces, 1978-99

It is generally true in China as well as throughout the world that distance from economic centers is associated with the limited market access. The influx of goods and technologies become more expensive and the exportations to partners gain less profit, for the burden of transport costs increases with distance, other things being equal (Venables and Limao 1999). The geographical attractiveness of a region, measured by its market access, is hence determined by its relative remoteness to the economic center. The greater the market access is, the higher the economy of scale is that an economy can pursue.

The gravity model developed by Bergstrand (1985), Deardorff (1995), and Guillaumont, Brun, and De Melo (1998), to name a few, demonstrates that the greater the

\footnotetext{
${ }^{5}$ The three municipalities directly under the Central Government-Beijing, Tianjin, and Shanghai-always have a much higher level of real GDP per capita than the other provinces. The real GDP per capita of Shanghai is at least five times the national average level, and that of Beijing and Tianjin is twice more.
} 
economic mass of the trade partners and the smaller the distance between them, the greater their bilateral trade volume is. More often, the GDP level is taken as the measure of economic mass, the attraction factor in gravity model. However, as to the resistance factor, real distance between two concerning regions is not necessarily the best proxy (Hummels 1999a, 1999b; Walz 1996; Crafts and Venables 2001). It is not the distance per se that hinders bilateral commerce; rather, it is the transport cost, which lessens the profit margin between cost of exporter and price of importer, that impedes trade. As developed in Limao and Venables (2000), transport cost is determined not only by the absolute geographical distance between trade partners but also by the development level of infrastructures of the itinerary concerned, namely, including that of the transit regions. The development level of the transportation infrastructure is thus vital for regional development.

The density of transport network is one of the important indices of infrastructure development, which may serve as measure of the infrastructure development level (Brot and Gérardin 2001; Catin, Ghio, and von Huffel 2002). The denser the transport network between two partners is, the higher the probability is that a better route for transport purposes can be identified. In the absence of tariffs on internal trade, transport cost captures most of the barriers of interprovincial trade. For a given real distance, the better the infrastructure development of itinerary is, the lower the transport cost is. Luo (2001) shows that the distance adjusted by infrastructure development level serves as a better proxy of resistance factor.

Growth theory suggests that regional growth rate is conditioned by its initial development level. If the initially poorer always tends to grow faster than the initially richer, it is a case of absolute convergence. However, other than the initial development level, regions may be heterogeneous in many other aspects, such as investment rate and demographic growth rate (Solow 1956; Swan 1956; Barro 1991; Barro and Sala-i-Martin 1991, 1992a, 1992b, 1996). It may not be reasonable to consider that all Chinese regions have the same development capacity in the long run. The theory of conditional convergence, which emphasizes the regional long-term development difference and its determinations, corresponds more closely to the reality: the farther away an economy is from its own longterm development capacity, the faster its growth rate is (Bernard and Durlauf 1995; BenDavid 1997; Venables 1999; Ben-David and Kimhi 2000; Maureth 2001). In other words, an economy converges to its own steady state, which is not necessarily common for different regions (Funke and Strulik 1999). 
Therefore, the focal point turns to find out the factors that condition long-term development capacity. As suggested by Gallup, Sachs, and Mellinger (1999); Redding and Venables (2000); and Radelet and Sachs (1999), high transport costs will damage export performance and economic growth. This paper argues that the geographical position of a region, which influences its market access, constitutes an important determinant of regional economic performance. We will test the role of the effective remoteness of a region to the economic center in the Solow-type growth determination model and examine the effects of the location of infrastructure investment on regional growth to identify the most efficient way to favor western development.

\section{Peripheral Degree}

Geographically adjoining regions tend to share similar economic performance. Given the fact that climate and topology play an important role in influencing disease burdens, agricultural productivity, and location in transport costs, it is not surprising that the distribution of economic activities is spatially uneven (Gallup, Sachs, and Mellinger 1999; Henderson, Shalizi, and Venables 2000). The homogeneity of the adjacent regions demonstrates that geographical position may be an important factor that conditions economic growth, as detailed in Baumont and others (2000) and Davis and Weinstein (1997). This section concentrates on constructing a peripheral degree to measure the relative remoteness of the province in question to an economic center and examines the role of peripheral degree in regional growth.

To measure the market accessibility of a province to a domestic economic center (here, the coastal provinces), taking into account the relative importance of the economic size of different coastal provinces, we define its peripheral degree, noted as $P D$, as the weighted sum of the adjusted distance between this province and all the coastal provinces. ${ }^{6}$ The influence of the demand from a partner province on the economic performance of the province in question is positively correlated to the economic mass of the former. We weigh the adjusted distance between the province in question $(i)$ and a coastal province $(j)$ by the economic mass of the latter relative to that of coastal provinces in total to approximate the relative importance of the effective remoteness. The reason lies in that the farther away the province in question is from a great size coastal province, the more serious the disadvantage is that it suffers. We suppose that, other things being equal, the structure of demand is similar 
among different regions, namely, the percentage of demand satisfied by local production (and thus that satisfied by the production of other provinces) is the same, as suggested by Courcier and Laffay (1972). Taking the influence of the economic mass of various coastal provinces and that of the transport cost on market accessibility of the province in question into account, we define our peripheral degree as follows:

$$
P D_{i, t}=\sum_{j}\left(\text { Dist }_{i j, t} \times \frac{G D P_{j, t}}{\sum_{j} G D P_{j, t}}\right)
$$

where $P D_{i, t}$ represents the peripheral degree of province $i$ at time $t$; Dist $A_{i j, t}$ represents the real distance between province $i$ and province $j$ adjusted by the development level of infrastructure of the itinerary that connects these two provinces at time $t$, namely the adjusted distance between province $i$ and province $j$ at time $t$ suggested by Luo $(2001)^{7}$; GDP $P_{j, t}$ represents the real GDP of province $j$ at time $t$. Here, $j$ represents the coastal provinces, including Beijing, Tianjin, Hebei, Liaoning, Shanghai, Jiangsu, Zhejiang, Fujian, Shangdong, and Guangdong. ${ }^{8}$

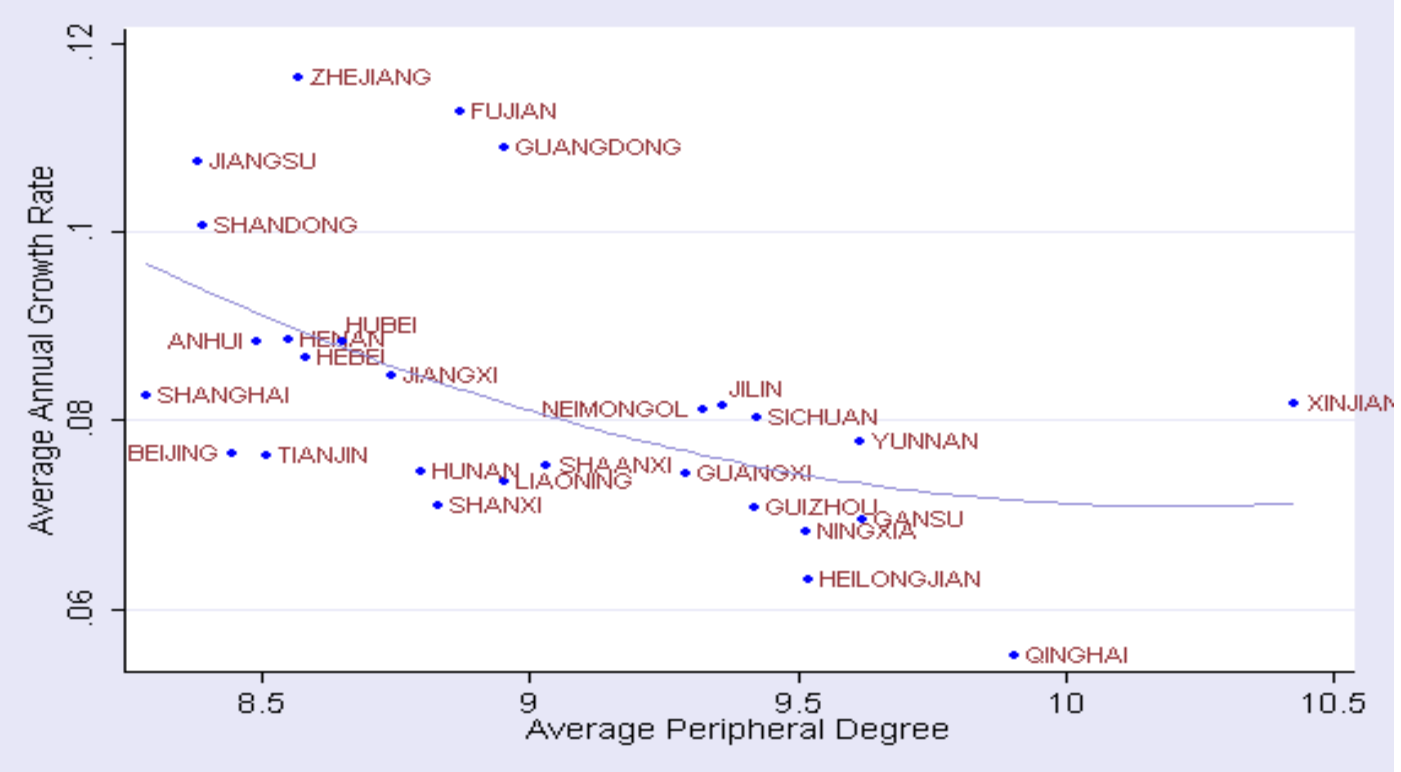

Figure 2. Relation between Peripheral Degree and Economic Growth Rate of Chinese Provinces, 1978-99

\footnotetext{
${ }^{6}$ In the case of China, all important harbors situate in coastal provinces. The relative remoteness to coastal provinces is positively correlated to the relative remoteness to international markets.

${ }^{7}$ See annex 2 for the construction of the adjusted distance.

${ }^{8}$ We exclude Hainan from our sample for its unique island characteristics.
} 
Figure 2 shows a strong correlation between peripheral degree and economic performance (in logarithmic forms): the higher the former is, the weaker the latter is. The important role of geographic position in regional development is also confirmed by the correlation study: the rank correlation between peripheral degree and real per capita GDP, both in logarithmic forms, is significantly negative with an average Spearman's Rho value of -0.5549 , and the probability of independence between these two variables is zero. ${ }^{9}$ By examining the Spearman's Rho value of each year, we find that this rank correlation becomes more and more significant as time passes (figure 3).

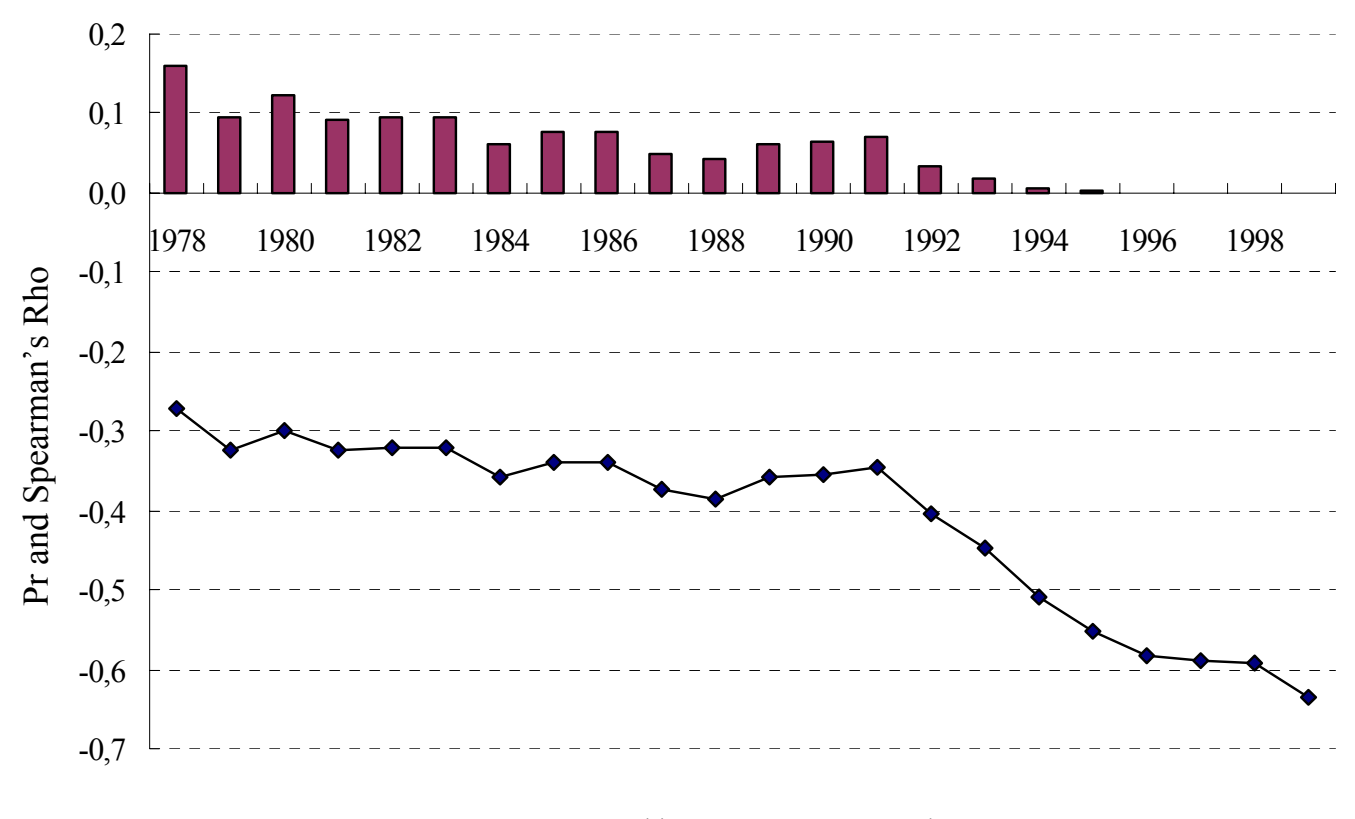

$\square \operatorname{Pr}>|\mathrm{t}| \longrightarrow$ Spearman's Rho

$\operatorname{Pr}>|t|$ stands for the probability of independence of $l d p$ and $l y t$.

Figure 3. Spearman's Rank Correlation between Peripheral Degree and Real Per Capita GDP of Chinese Provinces, 1978-99

We argue that geographical position plays an increasingly important role on regional development, as Chinese economy becomes more market-oriented. At the beginning of the economic reform in the late 1970s, the performance of the Chinese economy was distorted by the inefficient allocation of resources, and the regional development level did not well reflect

\footnotetext{
${ }^{9}$ To lessen the sensitivity to extreme values, we prefer Spearman's rank correlation estimation to standard Pearson correlation estimation. Spearman's rank correlation is calculated as Pearson's correlation computed on the ranks and average ranks (Spearman (1904), Conover (1980)). The significance is calculated using the approximation $p=\operatorname{tprob}\left(n-2, \rho \sqrt{n-2} / \sqrt{1-\rho^{2}}\right)$.
} 
the development capacity. ${ }^{10}$ As the economic reform deepens, regional comparative advantages become an important factor that determines the production structure. Favored by better access to foreign markets and benefited by the opening-up policies, coastal provinces grow much faster than inland ones, exacerbating the problem of unbalanced growth (Woo 1998). Given the fact that the geographical economic position of a province will not be altered significantly by fundamental external policy change, it is reasonable to predict that the core peripheral development pattern will continue. Appropriate policies may be needed to rebalance regional development.

\section{Growth Determination}

Using the macroeconomic data from Chinese Statistic Yearbooks, Comprehensive Statistic Data and Materials on 50 Years of New China, and China Regional Economy: A Profile of 17 Years of Reform and Opening Up, and the distance data from the Map of Communication Facilities of China, this section studies the determination of annual growth of Chinese provinces during 1978-99, emphasizing the role of geographical position.

The neoclassical growth model suggested by Solow-Swan (1956) emphasizes the effects of physical investment rate and demographic growth rate. The higher the ratio is of physical investment to GDP, the higher the productivity of effective labor is in long-run equilibrium, other things being equal. Trying to explain the enormous contribution of fixed capital in growth, the augmented Solow-Swan model argues the importance of human capital. The importance of the increasing return to scale renders the homogeneity of production function in various regions questionable, as suggested by the theory of new economic geography (Krugman 1991). Specialization and agglomeration amplify regional differences. ${ }^{11}$ Other than the demographic growth rate, the Solow-Swan model argues that the technological progress rate and depreciation rate of fixed investments influence regional growth. However, not all parameters that condition long-term economic performance are available or measurable. The omission of regional specific characteristics may lead to bias in estimation results. Hence, panel data estimation is preferable to cross-section estimation, for the former may capture the nonmeasurable specific characteristics in the fixed-effect model. We also introduce year dummies to control for the short-term effects.

\footnotetext{
${ }^{10}$ Pursuing the sake of "political security" and being aware of the "critical threat from the foreign capitalists," the Chinese government allocated a great deal of its industrial investment in the inland provinces during its "planned-economy" period. Subordinated to the "political goal," the comparative advantages of various provinces were not well considered before economic reform.

${ }^{11}$ See Ricci 1999, Krugman (1995), Puga (1999), Quah (2001), and Venables (2000).
} 
We start by testing the very simple hypothesis of absolute convergence (divergence) and estimate the following panel model:

$$
\ln \left(y_{i, t}\right)-\ln \left(y_{i, t-1}\right)=\alpha+\rho \ln \left(y_{i, t-1)}\right)+\sum_{t=1979}^{1998} \chi_{t} d u m m y_{t}+\varepsilon_{i, t}
$$

The first equation in table 2 shows that the initial development level $\ln \left(y_{i, t-1}\right)$ plays a significant role on regional growth. However, bearing in mind that Chinese provinces are heterogeneous, we do not think it reasonable to admit the hypothesis of their long-term steady state homogeneity - the premise of the existence of absolute convergence (divergence). As we have shown in the preceding section that geographical position, which represents regional market accessibility, may play an important role in influencing economic performance, we introduce the variable of peripheral degree, noted as $P D_{i, t}$, into our estimation:

$$
\ln \left(y_{i, t}\right)-\ln \left(y_{i, t-1}\right)=\alpha+\rho \ln \left(y_{i, t-1}\right)+\theta \ln \left(P D_{i, t}\right)+\sum_{t=1979}^{1998} \chi t d u m m y_{t}+\varepsilon_{i, t}
$$

In the second equation, the variable $\ln \left(y_{i, t-1}\right)$ continues to be significantly negative, which signifies conditional convergence. As predicted, the variable $P D_{i, t}$ plays a negative role on regional growth. The omission of this pertinent variable biases estimation results.

According to the Solow-Swan model, we suppose that production function is of the type of Cobb-Douglas:

$$
\ln \left(y_{i, t}\right)-\ln \left(y_{i, t-1}\right)=\vartheta+v \ln \left(y_{i, t-1}\right)+\gamma \ln \left(s_{i, t}\right)+\eta \ln \left(n_{i, t}+g_{i, t}+\delta_{i, t}\right)+\varepsilon_{i, t}
$$

where $s$ stands for the ratio of physical investment to GDP; $n$ the demographic growth rate; $g$ the technology progress, and $\delta$ the depreciation rate of physical investment. Many precedent studies on regional growth, such as that of Mankiw, Romer, and Weil (1992), suppose that the sum of these two parameters is homogeneously equal to 0.05 . However, in the case of China, it seems that this hypothesis is questionable given the fact that Chinese provinces are so different from one another. Due to the data unavailability of $g$ and $\delta$, we prefer to leave their influences implicitly into fixed effects:

$$
\ln \left(y_{i, t}\right)-\ln \left(y_{i, t-1}\right)=\alpha+\rho \ln \left(y_{i, t-1}\right)+\theta \ln \left(P D_{i, t}\right)+\gamma \ln \left(s_{i, t}\right)+\zeta \ln \left(n_{i, t}\right)+\sum_{t=1979}^{1998} \chi t d u m m y_{t}+\varepsilon_{i, t}
$$


The significance of the demographic growth rate in the third equation is consistent to the prediction of growth theory. The nonsignificance of the investment ratio may be the results of the fact that economic profit optimization, represented by marginal return equalization, may be sacrificed for regional development goals; the location of the physical investment does not respond well to market demand.

Given the significant difference between coastal and inland regions, according to the Chow test, we estimate the two subsamples separately in equations 4 and 5. As figure 2 shows, the relationship between peripheral degree and growth rate is not linear. To further investigate the role of peripheral degree, we add two supplementary variables, $\left[\ln \left(P D_{i, t}\right)\right]^{2}$ and $\ln \left(P D_{i, t}\right) \times \ln \left(y_{i, t-1}\right)$ into our model:

$$
\begin{aligned}
\ln \left(y_{i, t}\right)-\ln \left(y_{i, t-1}\right)= & \alpha+\beta \ln \left(y_{i, t-1}\right)+\theta \ln \left(P D_{i, t}\right)+\gamma \ln \left(s_{i, t}\right)+\eta \ln \left(n_{i, t}\right) \\
& +\zeta \ln \left[\left(P D_{i, t}\right)\right]^{2}+\beta_{1}\left[\ln \left(P D_{i, t}\right) \times \ln \left(y_{i, t-1}\right)\right] \\
& +\sum_{t=1979}^{1998} \chi_{t} d_{u m m y_{t}}+\varepsilon_{i, t}
\end{aligned}
$$

The sixth equation shows that for the coastal provinces the variable $\left[\ln \left(P D_{i, t}\right)\right]^{2}$ plays a significantly positive role on regional growth, which implies that the higher the peripheral degree is, the weaker the growth rate is, while such negative effects decrease as its value increases. ${ }^{12}$ The interactive term $\ln \left(P D_{i, t}\right) \times \ln \left(y_{i, t-1}\right)$ is also significantly positive, which signifies that for a given level of peripheral degree, the higher the initial development level is, the higher the regional growth rate is. According to the classical growth model, as suggested by the first equation, the convergence effects are captured by the coefficient of the variable $\ln \left(y_{i, t-1)}\right.$ :

$$
\frac{\partial\left\lfloor\ln \left(y_{i, t}\right)-\ln \left(y_{i, t-1}\right)\right\rfloor}{\partial \ln \left(y_{i, t-1}\right)}=\beta
$$

However, once we have controlled for the role of peripheral degree, as suggested by the sixth equation, the effects of convergence become:

$$
\frac{\partial\left\lfloor\ln \left(y_{i, t}\right)-\ln \left(y_{i, t-1}\right)\right\rfloor}{\partial \ln \left(y_{i, t-1}\right)}=\beta+\beta_{1} \ln \left(P D_{i, t}\right) .
$$

\footnotetext{
${ }^{12}$ The econometric results of the sixth equation vividly corroborates our figure 2 , when the peripheral degree is modest, the negative effect is great; when it is very high, further increase of geographic remoteness will lead to less economic performance loss.
} 
In other words, the size of convergence effects is conditioned by the peripheral degree. The positive sign of the coefficient $\beta_{1}$ and the negative sign of the coefficient $\beta$ demonstrate that convergence effects decrease as we control for the geographical economic position and the geographic remoteness limits convergence of the coastal province, other things being equal. For the subsample of the inland provinces, these two additional variables are not that significant, which implies that over a certain limit the negative role of the geographic remoteness tends to be linear. We hence consider equations 5 and 6 for the growth determination specification for inland and coastal provinces respectively.

The convexity of the peripheral degree on regional growth signifies the trap of remoteness that western provinces suffer. As the famous "liquidity trap," when the interest rate is lower than a certain level, its further reduction may not be able to induce private investment. When peripheral degree is high, great improvement will be needed to encourage local performance.

Table 2. Provincial Growth Determination: Role of Peripheral Degree, 1978-99

Dependent variable : $\ln \left(y_{i, t}\right)-\ln \left(y_{i, t-1}\right)$

\begin{tabular}{|c|c|c|c|c|c|c|c|}
\hline & $\begin{array}{l}\text { National } \\
\text { (1) }\end{array}$ & $\begin{array}{l}\text { National } \\
\text { (2) }\end{array}$ & $\begin{array}{l}\text { National } \\
\text { (3) }\end{array}$ & $\begin{array}{l}\text { Coast } \\
\text { (4) }\end{array}$ & $\begin{array}{l}\text { Inland } \\
\text { (5) }\end{array}$ & $\begin{array}{l}\text { Coast } \\
\text { (6) }\end{array}$ & $\begin{array}{l}\text { Inland } \\
\text { (7) }\end{array}$ \\
\hline $\ln \left(y_{i, t-1}\right)$ & $-0.044 * * *$ & $-0.082 * * *$ & $-0.066^{* * *}$ & $-0.061 * * *$ & $-0.137 * * *$ & $-1.397 * * *$ & $-0.661 * *$ \\
\hline & $(-3.47)$ & $(-5.35)$ & $(-4.47)$ & $(-2.65)$ & $(-5.20)$ & $(-3.77)$ & $(-2.04)$ \\
\hline $\ln \left(P D_{i, t}\right)$ & & $-0.197 * * *$ & $-0.168 * * *$ & -0.085 & $-0.254 * * *$ & $-5.275^{* * *}$ & $-2.187 * *$ \\
\hline & & $(-4.26)$ & $(-3.56)$ & $(-1.44)$ & $(-3.11)$ & $(-3.49)$ & $(-2.13)$ \\
\hline $\ln \left(s_{i, t}\right)$ & & & -0.003 & 0.005 & -0.013 & 0.024 & -0.013 \\
\hline & & & $(-0.30)$ & $(0.35)$ & $(-1.02)$ & $(1.59)$ & $(-1.04)$ \\
\hline $\ln \left(n_{i, t}\right)$ & & & $-1.066^{* * *}$ & $-0.747 * *$ & $-0.798^{*}$ & $-0.839 * * *$ & $-0.703^{*}$ \\
\hline $\ln \left(P D_{i, t}\right) \times \ln \left(P D_{i, t}\right)$ & & & $(-4.35)$ & $(-2.58)$ & $(-1.95)$ & $\begin{array}{c}(-2.97) \\
0.273 * * *\end{array}$ & $\begin{array}{l}(-1.71) \\
0.106^{*}\end{array}$ \\
\hline $\ln \left(y_{i, t-1}\right) \times \ln \left(P D_{i, t}\right)$ & & & & & & $\begin{array}{c}(3.40) \\
0.144 * * *\end{array}$ & $\begin{array}{l}(1.95) \\
0.054\end{array}$ \\
\hline Constant & $\begin{array}{c}0.201 * * * \\
(5.24)\end{array}$ & $\begin{array}{c}2.026^{* * * *} \\
(4.71)\end{array}$ & $\begin{array}{c}1.731^{* * *} \\
(4.01)\end{array}$ & $\begin{array}{l}1.016^{*} \\
(1.88)\end{array}$ & $\begin{array}{c}2.678^{* * *} \\
(3.58)\end{array}$ & $\begin{array}{c}(3.61) \\
25.827^{* * *} \\
(3.60)\end{array}$ & $\begin{array}{c}(1.58) \\
11.552^{* *} \\
(2.37)\end{array}$ \\
\hline Adjusted R square & 0.5025 & 0.5187 & 0.5585 & 0.7192 & 0.5325 & 0.7391 & 0.5412 \\
\hline Observation number & 588 & 588 & 568 & 208 & 360 & 208 & 360 \\
\hline
\end{tabular}

Note: $t$-students are in brackets. ${ }^{*}$ significant in 10 percent; ${ }^{* *}$ significant in 5 percent; ${ }^{* * *}$ significant in 1 percent. $\ln \left(y_{i, t-1}\right)$ stands for initial real GDP per capita in logarithmic form; $\ln \left(P D_{i, t}\right)$ peripheral degree in logarithmic form; $\ln \left(s_{i, t}\right)$ physical investment ratio in logarithmic form; $\ln \left(n_{i, t}\right)$ population growth rate in logarithmic form. For simplicity, the time dummies are not represented in the table. 


\section{Simulations}

An improvement of transportation facilities reduces the peripheral degree of the concerned provinces and favors their economic performance. Hence, the infrastructure investment policies are important to regional balanced growth. The peripheral degree, by construction, is determined by the distance between the province in question and the national economic center and by the infrastructure development level of the transit economies. A similar improvement of transportation facilities in different provinces does not lead to the same modification of peripheral degree in different provinces. As shown in the following box, an increase of transportation network density in one province does not only lead to the change of its own peripheral degree; it also leads to that of the other concerned provinces.

\section{Transportation Network Density and Peripheral Degree}

The change of the transportation network density $\left(D_{v, t}\right)$ in province $v$ leads to the modification of the peripheral degree of the concerned provinces $i\left(P D_{i, t}\right)$.

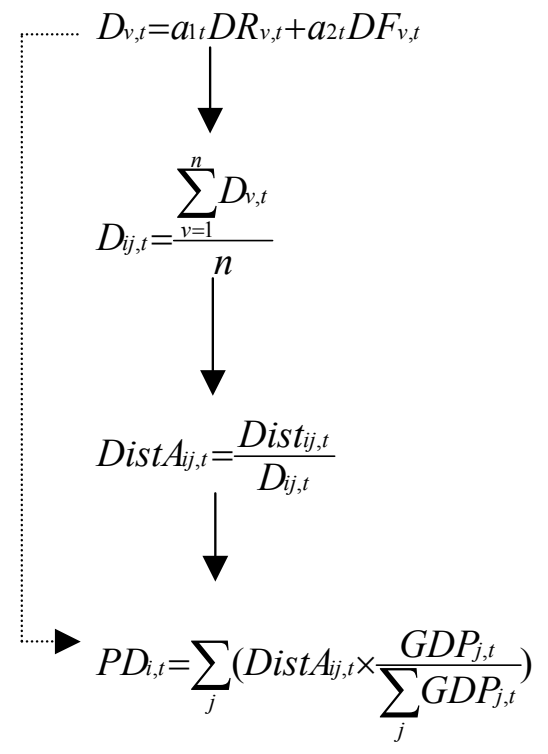

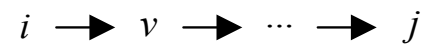

$n$ provinces

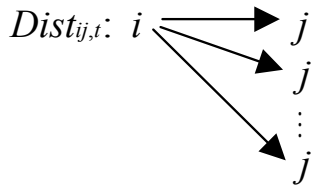

$\operatorname{Dist}_{i j, t}=a_{1 t} \operatorname{Dist}_{i j, t}+a_{2 t} \operatorname{Dist}_{i j, t}$

As to a province $i$, all modification of the transportation network locates in a province $v$, which situates in its itinerary to the coastal provinces, will lead to a modification of its peripheral degree. As to a province $v$, an improvement of its transportation infrastructure favors all provinces $i$ that cross it to join the coastal provinces. The heavier the traffic is that transits through province $v$, in which case province $v$ is considered as a transportation hub, the more provinces will benefit from its transportation facility improvement, and the greater are its effects on the reduction of the peripheral degree of the concerned provinces. 
In this section, we simulate the effects of a hypothetical increase of 10 percent in the transportation network density in each province, as follows, on the growth of the whole China and of the different regions, to evaluate the effects of the location of the infrastructure investment on regional balanced growth.

First, using the value of the peripheral degree that we have constructed with the observed value of the initial development level, the physical investment rate, and the demographic growth rate of all provinces, and applying the values of the coefficients $\left(\alpha, \rho, \theta, \gamma, \zeta, \chi_{t}\right)$ that we have estimated in table 2 , we calculate the estimated value of the dependant variable " $\ln \left(y_{i, t}\right)-\ln \left(y_{i, t-1}\right)$ ", noted as gaesi,t, using the third estimation in table 2:

$$
\begin{aligned}
\ln \left(y_{i, t}\right)-\ln \left(y_{i, t-1}\right)= & \alpha+\rho \ln \left(y_{i, t-1}\right)+\theta \ln \left(P D_{i, t}\right)+\gamma \ln \left(s_{i, t}\right)+\zeta \ln \left(n_{i, t}\right) \\
& +\sum_{t=1979}^{1998} \chi_{t} d u m m y_{t}+\varepsilon_{i, t}
\end{aligned}
$$

Second, we multiply the transportation network density of the province $v$ $(v=1,2,3, \ldots 28)$ by 110 percent, so we obtain a new value of $P D_{i, t}$, noted as $P D(v)_{i, t}$, due to the modification of $D_{v, t}$.

Third, we put the new value of $P D(v)_{i, t}$ into the equation in replace of $P D_{i, t}$ to calculate the new value of the estimated variable $" \ln \left(y_{i, t}\right)-\ln \left(y_{i, t-1}\right) "$, noted as gaes $(v)_{i, t}$.

Fourth, we define gadif( $(v)_{i, t}=$ gaes $(v)_{i, t}-$ gaes $i, t$, which stands for the increase of the growth rate of province $i$ in year $t$ due to the hypothetical increase of the transportation network density in province $v$.

Fifth, to take into account the difference of the economic size of each province, we calculate the weighted average growth effects due to the modification of $D_{v, t}$, noted as $\operatorname{gaeff}(v)_{t}$ :

$$
\operatorname{gaeff}(v)_{t}=\sum_{i}^{n}\left[\operatorname{gadif}(v)_{i, t} \times \frac{P I B_{i, t}}{\sum_{i}^{n} P I B_{i, t}}\right]
$$

The underlying idea lies in the notion that the larger is the economic size of the province in question in comparison with that of the whole group, the greater are the effects of the improvement of its economic performance on the growth of the group. 
Finally, to evaluate the effects of the change of $D_{v, t}$ in each province $v$ on the growth of different groups of provinces and hence on the regional balanced growth, we calculate the following ratios:

1) $i \in$ all Chinese provinces, gaeff $(v) t$ stands for the growth effects on the whole Chinese economy due to a 10 percent increase in the density of the transportation network in province $v$ in year $t$, noted as gaeff $0(v) t$

2) $i \in$ all coastal provinces, gaeff(v)t stands for the growth effects on the coastal region due to a $10 \%$ increase in the density of the transportation network in province $v$ in year $t$, noted as gaeff $1(v) t$

3) $i \in$ all inland provinces, gaeff $(v)_{t}$ stands for the growth effects on the inland region due to a 10 percent increase in the density of the transportation network in province $v$ in year $t$, noted as gaeff $2(v) t$

4) $i \in$ all western provinces, gaeff(v)t stands for the growth effects on the western region due to a 10 percent increase in the density of the transportation network in province $v$ in year $t$, noted as gaeff $3(v) t$

For simplicity, we calculate the following variables to study the average induced effects on the whole period 1978-1999 (table 3): ${ }^{13}$

$$
\begin{aligned}
& \text { gaeff } 0(v) m=\frac{\sum_{1979}^{1999} \text { gaeff } 0(v) t}{21} \\
& \text { gaeff } 1(v) m=\frac{\sum_{1979}^{1999} \text { aaeff } 1(v) t}{21} \\
& \text { gaeff } 2(v) m=\frac{\sum_{1979}^{1999} g a e f f 2(v) t}{21} \\
& \text { gaeff } 3(v) m=\frac{\sum_{1979}^{1999} g a e f f 3(v) t}{21}
\end{aligned}
$$

As the first column "national" shows, to generate the largest impacts on the growth of the whole China, we should locate the infrastructure investments in the coastal provinces, in particular, in Shandong, Jiangsu, and Hebei. Given the economic size of the coastal provinces and their role as economic centers, it is not surprising that the improvement of the

\footnotetext{
${ }^{13}$ The induced effects on the growth of different groups of provinces in each year are available upon request.
} 
transportation network in these provinces results in substantial effects on the weighted average growth of China as a whole. However, such favorable growth effects concentrate mainly in coastal regions, as shown the second column "coastal." ${ }^{14}$ The rapid growth in coastal provinces will enlarge the regional development gap, even though this growth pattern might be an efficient way to encourage national growth.

Table 3. Regional Growth Induced by 10 percent Hypothetical Transport Network Density Increase in Different Provinces (province in question included)

\begin{tabular}{|c|c|c|c|c|c|c|c|}
\hline \multicolumn{2}{|c|}{ National } & \multicolumn{2}{|c|}{ Coastal } & \multicolumn{2}{|c|}{ Inland } & \multicolumn{2}{|c|}{ West } \\
\hline Province & gaeff $0(v) m$ & Province & gaeff $1(v) m$ & Province & gaeff $2(v) m$ & Province & gaeff $3(v) m$ \\
\hline Qinghai & 0.03 & Shanxi & $\ldots$ & Qinghai & 0.07 & Nei Mongol & $\ldots$ \\
\hline Xinjiang & 0.03 & Nei Mongol & $\ldots$ & Xinjiang & 0.07 & Jilin & $\ldots$ \\
\hline Nei Mongol & 0.13 & Jilin & $\ldots$ & Nei Mongol & 0.27 & Heilongjiang & $\ldots$ \\
\hline Ningxia & 0.26 & Heilongjiang & $\ldots$ & Ningxia & 0.57 & Xinjiang & 0.18 \\
\hline Gansu & 0.35 & Guangxi & $\ldots$ & Gansu & 0.77 & Qinghai & 0.19 \\
\hline Yunnan & 0.39 & Sichuan & $\ldots$ & Yunnan & 0.87 & Ningxia & 1.62 \\
\hline Heilongjiang & 0.55 & Guizhou & $\ldots$ & Heilongjiang & 1.24 & Tianjin & 1.70 \\
\hline Guangxi & 0.61 & Yunnan & $\ldots$ & Guangxi & 1.36 & Gansu & 2.16 \\
\hline Guizhou & 0.69 & Shaanxi & $\ldots$ & Guizhou & 1.55 & Yunnan & 2.47 \\
\hline Jilin & 1.26 & Gansu & $\ldots$ & Tianjin & 1.77 & Jiangxi & 2.61 \\
\hline Shanxi & 1.59 & Qinghai & $\ldots$ & Beijing & 2.71 & Beijing & 2.72 \\
\hline Shaanxi & 1.67 & Ningxia & $\ldots$ & Jilin & 2.83 & Guangxi & 3.88 \\
\hline Sichuan & 1.85 & Xinjiang & $\ldots$ & Shanxi & 3.55 & Shanxi & 4.05 \\
\hline Tianjin & 2.72 & Jiangxi & 1.04 & Shaanxi & 3.73 & Guizhou & 4.41 \\
\hline Jiangxi & 3.03 & Anhui & 1.16 & Fujian & 3.78 & Fujian & 4.83 \\
\hline Beijing & 4.70 & Tianjin & 3.49 & Sichuan & 4.04 & Liaoning & 5.03 \\
\hline Anhui & 5.80 & Hubei & 3.80 & Jiangxi & 5.50 & Shanghai & 6.54 \\
\hline Hunan & 7.80 & Henan & 3.99 & Shanghai & 6.68 & Shandong & 7.09 \\
\hline Fujian & 8.48 & Hunan & 4.07 & Liaoning & 9.84 & Zhejiang & 7.61 \\
\hline Hubei & 9.68 & Beijing & 6.32 & Guangdong & 10.23 & Jiangsu & 7.86 \\
\hline Liaoning & 9.74 & Shanghai & 9.68 & Zhejiang & 10.39 & Hebei & 9.40 \\
\hline Henan & 10.21 & Liaoning & 12.28 & Jiangsu & 10.80 & Shaanxi & 10.58 \\
\hline Shanghai & 10.54 & Fujian & 13.67 & Shandong & 10.94 & Guangdong & 10.79 \\
\hline Guangdong & 12.80 & Guangdong & 14.86 & Anhui & 11.44 & Sichuan & 10.86 \\
\hline Zhejiang & 14.33 & Zhejiang & 17.52 & Hunan & 12.44 & Anhui & 10.98 \\
\hline Hebei & 17.87 & Hebei & 20.24 & Hebei & 15.00 & Hunan & 14.34 \\
\hline Jiangsu & 19.05 & Jiangsu & 25.78 & Hubei & 16.90 & Henan & 16.13 \\
\hline Shandong & 20.31 & Shandong & 27.90 & Henan & 17.67 & Hubei & 19.89 \\
\hline
\end{tabular}

Note: Figures are presented in 1/10000. " ..." stands for the figures inferior to 0.0000005 . For example, a 10 percent increase in the transport network density in Shandong province leads to a $20.31 \times 10^{-4}$ increase of the growth rate of the whole China. Coastal provinces are marked in italics; transport hubs are marked in bold.

As the third column "inland" shows, to stimulate the economic performance of the inland provinces, which are actually lagging behind, we should locate the investments in the central provinces transportation hubs of Henan, Hubei, and Hunan. This location choice also maximizes the favorable effects on the growth of the western provinces, as shown in the last column. The improvement of the transportation facilities in these central provinces leads to the greatest impacts on the rapid growth of the western provinces. As the third column "inland" shows, even if the growth of the coastal provinces is not integrated in the variable gaeff $2(v) m$, the improvement of the transportation network in certain coastal provinces, in

\footnotetext{
${ }^{14}$ Here we have even neglected the great multiplier effect of infrastructure investment on local growth.
} 
particular Hebei, generates greater induced effects on the growth of the inland provinces than that in most of the other inland provinces. If we focus on the induced effects on growth in western provinces, as shown in the last column "West," the effects of the investments in the central provinces of Hubei, Henan, and Hunan are the largest. In addition, the induced effects of the investments in some coastal or central provinces, such as Guangdong, Anhui, and Hebei, are greater than those in most of the remote western provinces.

To study the effects of an improvement of transportation network density in one province on the growth of the other provinces and verify the robustness of our simulation results, we calculate the same ratios excluding the province in question. We calculate $\operatorname{gaeff}(v)_{t}=\sum_{i}^{n}\left[\operatorname{gadif}(v)_{i, t} \times \frac{P I B_{i, t}}{\sum_{i}^{n} P I B_{i, t}}\right]$ for all $i \neq v$ to purge the effects of the investment on local growth. $^{15}$

Table 3 bis. Regional Growth Induced by 10 Percent Hypothetical Transport Network Density Increase in Different Provinces (province in question excluded)

\begin{tabular}{|c|c|c|c|c|c|c|c|}
\hline \multicolumn{2}{|c|}{ National } & \multicolumn{2}{|c|}{ Coastal } & \multicolumn{2}{|c|}{ Inland } & \multicolumn{2}{|c|}{ West } \\
\hline Province & gaeff $0(v) m$ & Province & gaeff $1(v) m$ & Province & gaeff $2(v) m$ & Province & gaeff $3(v) m$ \\
\hline Nei Mongol & $\ldots$ & Shanxi & $\ldots$ & Nei Mongol & $\ldots$ & Nei Mongol & $\ldots$ \\
\hline Heilongjiang & $\ldots$ & Nei Mongol & $\ldots$ & Heilongjiang & $\ldots$ & Jilin & $\ldots$ \\
\hline Yunnan & $\ldots$ & Jilin & $\ldots$ & Yunnan & $\ldots$ & Heilongjiang & $\ldots$ \\
\hline Xinjiang & $\ldots$ & Heilongjiang & $\ldots$ & Xinjiang & $\ldots$ & Yunnan & $\ldots$ \\
\hline Qinghai & 0.02 & Guangxi & $\ldots$ & Qinghai & 0.04 & Xinjiang & $\ldots$ \\
\hline Sichuan & 0.04 & Sichuan & $\ldots$ & Sichuan & 0.09 & Qinghai & 0.11 \\
\hline Guangxi & 0.16 & Guizhou & $\ldots$ & Gansu & 0.35 & Sichuan & 0.34 \\
\hline Gansu & 0.16 & Yunnan & $\ldots$ & Guangxi & 0.37 & Gansu & 1.03 \\
\hline Ningxia & 0.19 & Shaanxi & $\ldots$ & Ningxia & 0.43 & Guangxi & 1.17 \\
\hline Guizhou & 0.38 & Gansu & $\ldots$ & Guizhou & 0.86 & Ningxia & 1.22 \\
\hline Shanxi & 0.79 & Qinghai & $\ldots$ & Tianjin & 1.77 & Tianjin & 1.70 \\
\hline Jilin & 0.80 & Ningxia & $\ldots$ & Shanxi & 1.82 & Jiangxi & 2.61 \\
\hline Shaanxi & 0.96 & Xinjiang & $\ldots$ & Jilin & 1.86 & Guizhou & 2.62 \\
\hline Tianjin & 1.73 & Jiangxi & 1.04 & Shaanxi & 2.19 & Beijing & 2.72 \\
\hline Jiangxi & 2.14 & Anhui & 1.16 & Beijing & 2.71 & Shanxi & 4.05 \\
\hline Beijing & 2.90 & Tianjin & 1.70 & Jiangxi & 3.58 & Fujian & 4.83 \\
\hline Anhui & 4.49 & Beijing & 3.06 & Fujian & 3.78 & Liaoning & 5.03 \\
\hline Hunan & 6.34 & Hubei & 3.80 & Shanghai & 6.68 & Shanghai & 6.54 \\
\hline Shanghai & 6.50 & Henan & 3.99 & Anhui & 8.85 & Shaanxi & 6.88 \\
\hline Fujian & 7.39 & Hunan & 4.07 & Hunan & 9.41 & Shandong & 7.09 \\
\hline Hubei & 7.75 & Shanghai & 6.34 & Liaoning & 9.84 & Zhejiang & 7.61 \\
\hline Henan & 8.01 & Liaoning & 6.52 & Guangdong & 10.23 & Jiangsu & 7.86 \\
\hline Liaoning & 8.11 & Fujian & 10.46 & Zhejiang & 10.39 & Hebei & 9.40 \\
\hline Guangdong & 10.39 & Guangdong & 10.52 & Jiangsu & 10.80 & Guangdong & 10.79 \\
\hline Zhejiang & 12.38 & Zhejiang & 14.16 & Shandong & 10.94 & Anhui & 10.98 \\
\hline Jiangsu & 16.36 & Hebei & 17.85 & Hubei & 13.13 & Hunan & 14.34 \\
\hline Hebei & 16.48 & Jiangsu & 21.81 & Henan & 13.41 & Henan & 16.13 \\
\hline Shandong & 17.48 & Shandong & 23.63 & Hebei & 15.00 & Hubei & 19.89 \\
\hline
\end{tabular}

Note : Figures are presented in 1/10000. " ... " stands for the figures inferior to 0.0000005 . For example, a 10 percent increase in the transport network density of Shandong province leads to a $17.48 \times 10^{-4}$ increase of the growth rate of China as a whole (except Shandong). Coastal provinces are marked in italics; transport hubs are marked in bold.

\footnotetext{
${ }^{15}$ If the province $v$ is not a member of the group in question, the value of the ratio in table 3 bis is the same as the one in table 3 .
} 
As shown in table 3 bis, the infrastructure investments in the three central provinces of Henan, Hubei, and Hunan generate the largest induced effects on the growth of the western provinces, even when the effects on their local growth are excluded. That the infrastructure investments in the three central provinces of Henan, Hubei, and Hunan generate the largest induced effects on the growth of the western provinces, even when the effects on their local growth are excluded, confirms the vital importance of the improvement of transportation facilities in these provinces, which are densely crossed by traffics.

To test the robustness of our simulation results, we use equations 5 and 6 in table 2 for inland provinces and coastal provinces respectively, which consider the difference between these two regions. ${ }^{16}$ Our results show that it is always the improvement in central transportation hubs that generates the highest effects on regional balanced growth. ${ }^{17}$

\section{Regional Policy Suggestions}

We suggest developing the infrastructure of the provinces that are on the way of transportation from many western provinces to markets, namely, the transportation hubs of China. In fact, the market access of one province, and hence its long-term development, depends not only on its own infrastructure development but also on the infrastructure development of the transit provinces. To reduce the effective remoteness and to enlarge the market access of the western region, we should develop the infrastructure that connects the provinces to markets. Since the government finances most of the infrastructure investments, it is possible to carry them out in selected provinces to favor the West.

With the nonnegligible multiplier effect of infrastructure investment on local economic development, the additional investment in the coastal provinces may aggravate the unbalanced development of China. Further infrastructure developments within coastal regions may lead to the enforcement of agglomeration, which will accelerate regional growth of coastal regions relative to the western ones. Such policies violate the equity criterion.

Other things being equal, we suggest giving priority to the development of the western region to ensure basic infrastructure development. If the infrastructure is too poor for local enterprises to have the minimum demand because of market segmentation, the development of western region may be unrealizable due to the lack of microeconomic foundations. The

\footnotetext{
${ }^{16}$ See annex 3 for details.

${ }^{17}$ We have also simulated a 10 percent increase in the national average transportation network density to control for the effects of different hypothetical density increase in absolute value due to the different initial density of transportation network in each province. The ranking of the provinces regarding to the size of the induced growth effect stays the same. Results are available upon request.
} 
appropriate investment in the West is necessary to guarantee basic intraregional transportation facilities. However, while the development of the infrastructure inside the region facilitates intraregional transportation and enlarges the market of local enterprises, it does so only within the province itself. The political inclination to western regional development does not necessarily lead to the conclusion that all infrastructure investments should be located in the western region. To so locate infrastructure investments would entail the risk that, without a sufficient infrastructure development of the central region, trade volume between the East and the West would be limited. Because western provinces are far more underdeveloped, their local demands are modest and their technology and management are less advanced. The separation of East and West renders the investment in the West much less efficient.

To take the two criteria, equity and efficiency, into account at the same time, it is more advisable to locate infrastructure investments in the hubs of Henan, Hubei, and Hunan. As transportation hubs, although they may be less developed compared with the coastal provinces, they are already relatively developed, at least in terms of transportation conditions. For the specialty of infrastructure investment itself, the additional sum to a reasonably welldeveloped location generates greater positive effects than those to less-developed places. This is not to conclude that we should neglect the development of remote border provinces because of their current relative less developed situations. Developing the hubs favors the outward-looking production structure of the western region and facilitates the transfer of technology and management skills from East to West.

However, one potential problem that we must consider is that when we strengthen infrastructures, say, the transportation network, from the West to the East, we improve the accessibility of the eastern provinces to western markets. While this improved accessibility accelerates the development of the West, it has inherent risks insofar as the coastal and central regions can supply better goods at lower prices. For the sake of long-term growth of the West and thus of China as a whole some appropriate regional economic policies, such as regulations that reasonably protect the privileges of western local enterprises as infant industries, must be issued to limit this negative effect. In addition, given the fact that the infrastructure development level of some western provinces is too poor to provide basic facilities of transportation and that infrastructure investment itself generates a large multiplier effect on local development, it is reasonable to locate some infrastructure investment there to help to break the vicious cycle. In particular, investments in the provinces Sichuan and Shaanxi are recommended, given their important role in regional development. 
In short, we should take both the efficiency criterion and the equity criterion into consideration to choose locations of infrastructure investments. Because central hubs favor the balanced development of China, they are the best locations.

\section{Conclusions}

Infrastructure development is important for regional performance. Geographic remoteness to economic centers significantly hinders regional growth. Improving transportation facilities, which reduces transportation costs, increases the volume of trade and technology transfer. Targeted infrastructure investment in central transportation hubs favors the catching up of the western region most efficiently by optimizing market access.

\section{References}

Barro, R.J. 1991. "Economic Growth in a Cross Section of Countries." Quarterly Journal of Economics 106(2):407-43.

Barro, R.J., and X. Sala-i-Martin. 1991. "Convergence across States and Regions." Brooking Papers on Economic Activity, No.1:107-82.

Barro, R.J., and X. Sala-i-Martin. 1992a. "Convergence." Journal of Political Economy 100(2): 22351.

Barro R.J., and X. Sala-i-Martin. 1992b. "Regional Growth and Migration: a Japan-United States Comparison." Journal of the Japanese and International Economies 6:312-46.

Barro R.J., and X. Sala-i-Martin. 1996. La croissance économique. Collection sciences économiques, McGraw-Hill /Ediscience, Paris.

Baumont C., P. P. Combes, P. H. Derycke, and H. Jayet. éds. 2000. Economie géographique: les théories à l'épreuve des faits. Paris: Economica.

Ben-David, D. 1997. "Convergence Clubs and Subsistence Economies." National Bureau of Economic Research Working Paper 6267. Cambridge, Mass.

Ben-David D., and A. Kimhi. 2000. "Trade and the Rate of Income Convergence." National Bureau of Economic Research. National Bureau of Economic Research Working Paper 7462. Cambridge, Mass.

Bergstrand, J.H. 1985. "The Gravity Equation in International Trade: Some Microeconomic Foundations and Empirical Evidence." Review of Economics and Statistics (U.S.), 67:474-81.

Bernard A.B., and S. N. Durlauf. 1991. "Convergence in International Output." National Bureau of Economic Research. Working Paper 3717. Cambridge, Mass.

Brot J., and H. Gérardin. 2001. Infrastructure et développement. Paris: L'Harmattan.

Catin M., S. Ghio, and C. van Huffel. 2002. "Infrastructures de transport et intégration européenne: efficacité économique versus équité régionale." Revue d'Economie Politique, 112(3): 409-36.

Conover, W.J. 1980. Practical Nonparametric Statistics, $2^{\text {ème }}$ ed. New York: John Wiley \& Sons.

Courcier, M., and G. Lafay. 1972. "Simulation économique multinationale." Statistiques \& Etudes Financières, 1972/8, $4^{\text {ème }}$ trimestre.

Crafts N., and A. J. Venables. 2001. "Globalization in History: a Geographical Perspective." 
Accessible at $h t t p: / / w w w . l e s . a c . u k / s t a f f / a j v /$.

Deardorff, A. 1995. "Determinants of Bilateral Trade: Does Gravity Work in a Neoclassical World?" National Bureau of Economic Research Working Paper 5377. Cambridge, Mass.

Davis, D.R., and D. E. Weinstein. 1997. "Economic Geography and Regional Production Structure: an Empirical Investigation." National Bureau of Economic Research Working Paper 6093. Cambridge, Mass.

Démurger S., J. D. Sachs, W. T. Woo, and S. Bao. 2002. "Geography, Economic Policy and Regional Development in China." National Bureau of Economic Research Working Paper 8897. Cambridge, Mass.

Fujiata, M., P. Krugman, and A. J. Venables. (1999. The Spatial Economy: Cities, Regions and International Trade." Cambridge, Mass.: MIT Press.

Funke, M., and H. Strulik. 1999. "Regional Growth in West Germany: Convergence or Divergence." Economic Modelling 16: 489-502.

Gallup, J.L., J. D. Sachs, and A. D. Mellinger. 1999. "Geography and Economic Development." International Regional Science Review 22(2):179-232.

Guillaumont, P., J. F. Brun, and J. De Melo. 1998. "La distance abolie? Critères et mesure de la mondialisation du commerce extérieur." Etudes et documents du CERDI E98.30.

Henderson, J.V., S. Zhalizi, and A. J. Venables. 2000. "Geography and Development." World Bank Working Paper 2456. Washington, D.C.

Hummels, D. 1999a. "Toward a Geography of Trade Costs." Accessible at http://gsbwww.uchicago. edu/fac/david.hummels/research/vs/.

Hummels, D. 1999b. "Have International Transportation Costs Declined?" Accessible at http://gsbwww.uchicago.edu/fac/david.hummels.

Krugman, P. 1991. Geography and Trade. Cambridge, Mass: Leuwen University Press and MIT Press.

Krugman, P. 1995. "A Dynamic Spatial Model." National Bureau of Economic Research Working Paper 4219. Cambridge, Mass.

Limao, N., and A. J. Venables. 2001. "Infrastructure, Geographical Disadvantage and Transport Costs." World Bank Economic Review (International) 15(3):451-79.

Luo, X. 2001. "La mesure de la distance dans le modèle de gravité - une application au commerce bilatéral entre les provinces chinoises avec le Japon." Revue Région et Développement No.13:163-80

Mankiw, N.G., D. Romer, and D. N. Weil. 1992. "A Contribution to the Empirics of Economic Growth." Quarterly Journal of Economics 107(2):407-37.

Maureth, P.B. 2001. "Convergence, Geography and Technology." Structural Change and Economic Dynamics 12:247-76.

Puga, D. 1999. "The Rise and Fall of Regional Inequalities." European Economic Review 43:30334.

Radelet S., and J. D. Sachs. 1999. "Shipping Costs, Manufactured Exports and Economic Growth." HID Cambridge, Mass.

Redding S.J., and A. J. Venables. 2004. "Economic Geography and International Inequality." Journal of International Economics (Netherlands) 62(1):53-82.

Ricci, L.A. 1999. "Economic Geography and Comparative Advantage: Agglomeration versus Specialization." European Economic Review 43:357-77.

Quah, D. 2001. "Some Simple Arithmetic on How Income Inequality and Economic Growth Matter." Accessible at http://econ.lse.ac.uk/staff/dquah/p/0106iieg.pdf.

Solow, R.M. 1956. "A Contribution to the Theory of Economic Growth." Quarterly Journal of Economics 70(1):65-94.

Spearman, C. 1904. "The Proof and Measurement of Association between Two Things." American Journal of Psychology 15:72-101.

State Statistical Bureau of the People's Republic of China. China Statistical Yearbook. Beijing: China Statistics Press.

Swan, T.W. 1956. "Economic Growth and Capital Accumulation." Economic Record, 32: 334-61.

Venables, A.J. 1999. "Regional Integration Agreements: a Force for Convergence or Divergence." World Bank Working Paper 2260. Washington, D.C. 
Venables, A.J. 2000. "Winners and Losers from Regional Integration Agreements." Economic Journal, 113:747-61.

Venables, A.J., and N. Limao. 1999. "Geographical Disadvantage: a Heckscher-Ohlin-von Thunen Model of International Specialisation." Journal of International Economics 58:239-63.

Walz, U. 1996. "Transport Costs, Intermediate Goods, and Localized Growth." Regional Science and Urban Economics 26:671-95.

Woo, W.T. 1998. "Chinese Economic Growth: Sources and Prospects." In Michel Fouquin et Françoise Lemoine, eds., The Chinese Economy. London: Economica. 


\section{Annex 1. Map of China}

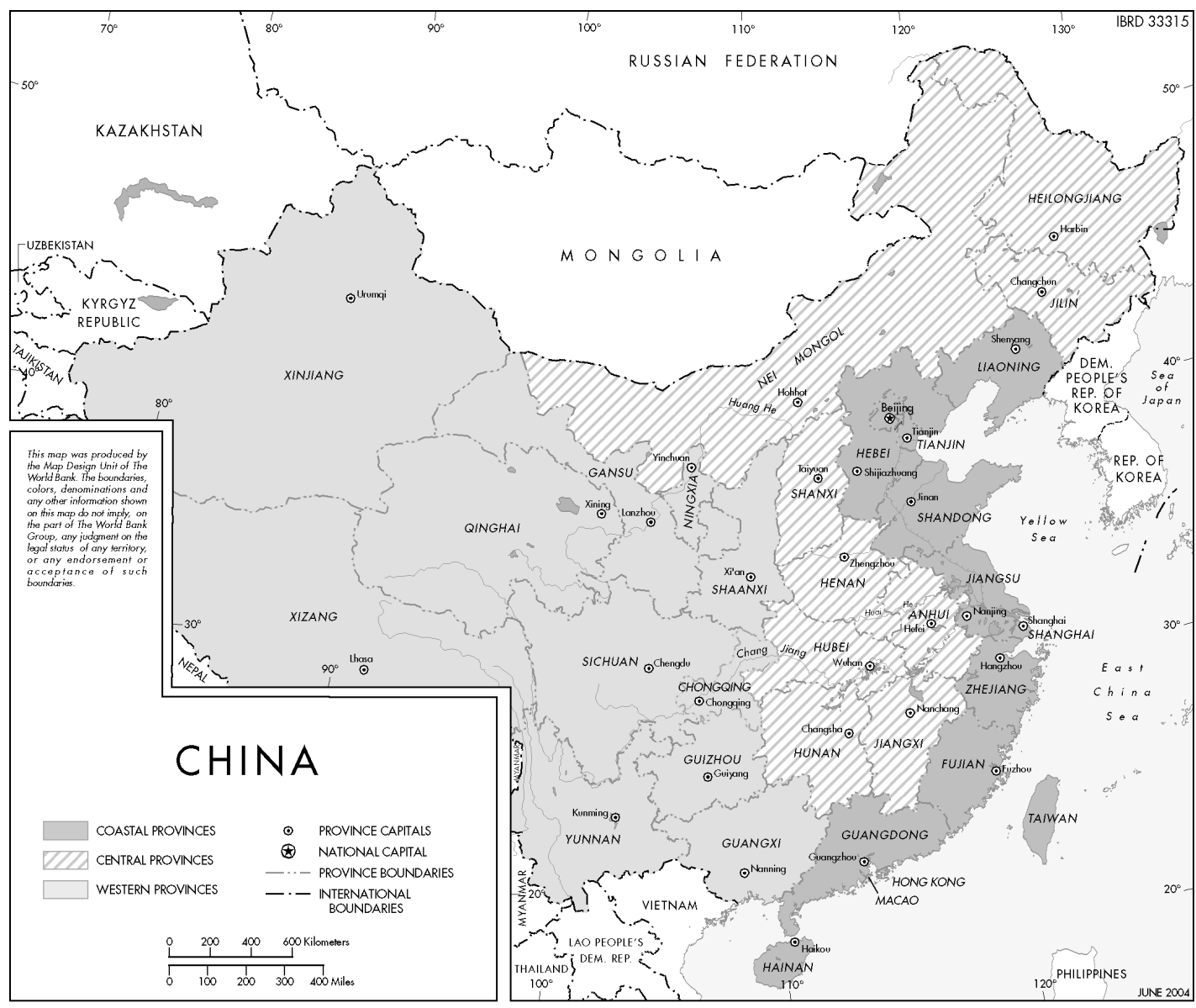




\section{Annex 2. Construction of the Adjusted Distance}

The construction of the adjusted distance between one province (province $\mathrm{j}$ ) and the province in question (province i) includes four steps:

1. For each province (noted as province v), we calculate its road density and railway density, noted as $D R_{v, t}$ and $D F_{v, t}$ respectively. Then, to better reflect the importance of road transportation and the railway transportation, we weight them with the road transportation volume and the railway transportation volume to get the transportation network index of the province $\left(D_{v, t}\right)$ :

$$
D_{v, t}=a_{1 t} D R_{v, t}+a_{2 t} D F_{v, t} .
$$

Where $a_{1 t}$ represents the percentage of the road transportation volume and $a_{2 t}$ represents that of the railway at time t. $a_{1 t}+a_{2 t}=1$.

2. For each two provinces (province $i$ and province $j$ ), we calculate the index of the transportation facility between them, noted $D_{i j, t}$. Suppose that to transport some goods from province i to province $\mathrm{j}$, it should go through $\mathrm{n}$ provinces (province $\mathrm{i}$ and $\mathrm{j}$ included), we take the index $D_{i j, t}$ as the simple average of the value of $D_{v, t}$ of these n provinces:

$$
D_{i j, t}=\frac{\sum D_{v, t}}{n}
$$

3. We define the real distance between province i and province $\mathrm{j}\left(D_{i s t} t_{i j, t}\right)$ as the weighted sum of their road distance $\left(\operatorname{Dist}_{i j, t}\right)$ and railway distance $\left(\operatorname{DistF}_{i j, t}\right)$.

$$
\text { Dist }_{i j, t}=a_{1 t} \text { Dist }_{i j, t}+a_{2 t} \text { DistF }_{i j, t}
$$

4. We define the adjusted real distance between province i and province $\mathrm{j}\left(\operatorname{DistA}_{i j, t}\right)$ as the result of their real distance divided by the index of their transportation facility.

$$
\operatorname{Dist}_{i j, t}=\text { Dist }_{i j, t} / D_{i j, t}
$$

For a given real distance, the adjusted real distance implies that, the better the transportation facility is, the less the adjusted distance is. The transportation facility "shortens" the economic distance between the two provinces by reducing the transportation cost. The adjusted real distance is a better proxy of the transportation cost. The shorter the adjusted real distance is, the less the trade obstacles between two partners and so the greater the volume of trade between them, other things being equal. The greater the trade volume is between two provinces, the better the market accessibility is to the other in the view of the province in question, and the influence of partner province's demand on the local market is greater. 


\section{Annex 3. Robustness Test}

Taking into account the difference between the coastal provinces and inland provinces and testing the robustness of the results of the ranking of the provinces, we calculated the estimated value of the dependant variable " $\ln \left(y_{i, t}\right)-\ln \left(y_{i, t-1}\right)$ ", noted as gaesi,t, separately. For coastal provinces:

$$
\begin{aligned}
\ln \left(y_{i, t}\right)-\ln \left(y_{i, t-1}\right)= & \alpha+\rho \ln \left(y_{i, t-1}\right)+\theta \ln \left(P D_{i, t}\right)+\gamma \ln \left(s_{i, t}\right)+\zeta \ln \left(n_{i, t}\right)+\tau\left[\ln \left(P D_{i, t}\right)\right]^{2}+ \\
& \beta_{1}\left[\ln \left(y_{i, t-1}\right) \times \ln \left(P D_{i, t}\right)\right]+\sum_{t=1979}^{1998} \chi_{t} d u m m y_{t}+\varepsilon_{i, t}
\end{aligned}
$$

and for inland provinces :

$$
\begin{aligned}
\ln \left(y_{i, t}\right)-\ln \left(y_{i, t-1}\right)= & \alpha+\rho \ln \left(y_{i, t-1}\right)+\theta \ln \left(P D_{i, t}\right)+\gamma \ln \left(s_{i, t}\right)+\zeta \ln \left(n_{i, t}\right) \\
& +\sum_{t=1979}^{1998} \chi_{t} d u m m y_{t}+\varepsilon_{i, t}
\end{aligned}
$$

Using the similar process stated in section 5, we have the simulation results as follows:

\begin{tabular}{|c|c|c|c|c|c|c|c|}
\hline \multicolumn{2}{|c|}{ National } & \multicolumn{2}{|c|}{ Coastal } & \multicolumn{2}{|c|}{ Inland } & \multicolumn{2}{|c|}{ West } \\
\hline Province & gaeff $0(v) m$ & Province & gaeff $1(v) m$ & Province & gaeff $2(v) m$ & Province & gaeff $3(v) m$ \\
\hline Qinghai & 0.05 & Shanxi & $\cdots$ & Xinjiang & 0.10 & Nei Mongol.. & $\cdots$ \\
\hline Xinjiang & 0.05 & Nei Mongol. & $\ldots$ & Qinghai & 0.11 & Jilin & $\ldots$ \\
\hline Nei Mongol. & 0.19 & Jilin & $\ldots$ & Nei Mongol. & 0.42 & Heilongjiang & $\ldots$ \\
\hline Ningxia & 0.39 & Heilongjiang & $\ldots$ & Ningxia & 0.87 & Xinjiang & 0.28 \\
\hline Gansu & 0.53 & Guangxi & $\ldots$ & Gansu & 1.17 & Qinghai & 0.30 \\
\hline Yunnan & 0.59 & Sichuan & $\ldots$ & Yunnan & 1.32 & Ningxia & 2.45 \\
\hline Heilongjiang & 0.84 & Guizhou & $\ldots$ & Heilongjiang & 1.88 & Tianjin & 2.57 \\
\hline Guangxi & 0.92 & Yunnan & $\ldots$ & Guangxi & 2.07 & Gansu & 3.28 \\
\hline Guizhou & 1.05 & Shaanxi & $\ldots$ & Guizhou & 2.35 & Yunnan & 3.74 \\
\hline Jilin & 1.91 & Gansu & $\ldots$ & Tianjin & 2.68 & Jiangxi & 3.97 \\
\hline Shanxi & 2.41 & Qinghai & $\ldots$ & Beijing & 4.12 & Beijing & 4.12 \\
\hline Shaanxi & 2.54 & Ningxia & $\ldots$ & Jilin & 4.30 & Guangxi & 5.89 \\
\hline Sichuan & 2.80 & Xinjiang & $\ldots$ & Shanxi & 5.39 & Shanxi & 6.15 \\
\hline Tianjin & 3.79 & Jiangxi & 2.60 & Shaanxi & 5.66 & Guizhou & 6.69 \\
\hline Jiangxi & 5.16 & Anhui & 2.88 & Fujian & 5.74 & Fujian & 7.33 \\
\hline Beijing & 6.77 & Hubei & 3.25 & Sichuan & 6.14 & Liaoning & 7.64 \\
\hline Anhui & 9.42 & Henan & 3.43 & Jiangxi & 8.35 & Shanghai & 9.93 \\
\hline Hunan & 10.36 & Hunan & 3.47 & Shanghai & 10.14 & Shandong & 10.76 \\
\hline Fujian & 11.58 & Tianjin & 4.69 & Liaoning & 14.93 & Zhejiang & 11.55 \\
\hline Liaoning & 12.64 & Beijing & 8.92 & Guangdong & 15.53 & Jiangsu & 11.92 \\
\hline Hubei & 13.31 & Liaoning & 10.76 & Zhejiang & 15.77 & Hebei & 14.27 \\
\hline Henan & 14.06 & Fujian & 16.27 & Jiangsu & 16.39 & Shaanxi & 16.05 \\
\hline Shanghai & 15.18 & Guangdong & 18.86 & Shandong & 16.60 & Guangdong & 16.38 \\
\hline Guangdong & 17.41 & Shanghai & 19.20 & Anhui & 17.36 & Sichuan & 16.48 \\
\hline Zhejiang & 22.07 & Zhejiang & 27.10 & Hunan & 18.87 & Anhui & 16.66 \\
\hline Hebei & 26.15 & Hebei & 28.88 & Hebei & 22.76 & Hunan & 21.76 \\
\hline Jiangsu & 32.56 & Jiangsu & 45.69 & Hubei & 25.64 & Henan & 24.48 \\
\hline Shandong & 35.28 & Shandong & 50.30 & Henan & 26.81 & Hubei & 30.18 \\
\hline
\end{tabular}

Table 3a. Regional Growth Induced by 10 Percent Hypothetical Transport Network Density Increase in Different Provinces, Distinguishing Coastal and Inland Provinces (province in question included)

Note : Figures are presented in 1/10000. " ..." stands for the figures inferior to 0.0000005 . For example, a 10 percent increase in the transport network density in Shandong province leads to a $35.28 \times 10^{-4}$ increase of the growth rate of the whole China. Coastal provinces are marked in italics; transport hubs are marked in bold. 
Table 3a bis. Regional Growth Induced by 10 Percent Hypothetical Transport Network Density Increase in Different Provinces, Distinguishing Coastal and Inland Provinces (province in question excluded)

\begin{tabular}{|c|c|c|c|c|c|c|c|}
\hline \multicolumn{2}{|c|}{ National } & \multicolumn{2}{|c|}{ Coastal } & \multicolumn{2}{|c|}{ Inland } & \multicolumn{2}{|c|}{ West } \\
\hline Province & gaeff $0(v) m$ & Province & gaeff $1(v) m$ & Province & gaeff $2(v) m$ & Province & gaeff $3(v) m$ \\
\hline Nei Mongol. & $\ldots$ & Shanxi & $\ldots$ & Nei Mongol. & ... & Nei Mongol.. & \\
\hline Heilongjiang & $\ldots$ & Nei Mongol.. & $\ldots$ & Heilongjiang & $\ldots$ & Jilin & $\ldots$ \\
\hline Yunnan & $\ldots$ & Jilin & $\ldots$ & Yunnan & $\ldots$ & Heilongjiang & $\ldots$ \\
\hline Xinjiang & $\ldots$ & Heilongjiang & $\ldots$ & Xinjiang & $\ldots$ & Yunnan & . \\
\hline Qinghai & 0.03 & Guangxi & $\ldots$ & Qinghai & 0.06 & Xinjiang & 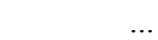 \\
\hline Sichuan & 0.06 & Sichuan & $\ldots$ & Sichuan & 0.14 & Qinghai & 0.17 \\
\hline Gansu & 0.24 & Guizhou & $\ldots$ & Gansu & 0.53 & Sichuan & 0.52 \\
\hline Guangxi & 0.25 & Yunnan & $\ldots$ & Guangxi & 0.57 & Gansu & 1.56 \\
\hline Ningxia & 0.29 & Shaanxi & $\ldots$ & Ningxia & 0.65 & Guangxi & 1.77 \\
\hline Guizhou & 0.58 & Gansu & $\ldots$ & Guizhou & 1.31 & Ningxia & 1.85 \\
\hline Shanxi & 1.20 & Qinghai & $\ldots$ & Tianjin & 2.68 & Tianjin & 2.57 \\
\hline Jilin & 1.22 & Ningxia & $\ldots$ & Shanxi & 2.76 & Jiangxi & 3.97 \\
\hline Shaanxi & 1.45 & Xinjiang & $\ldots$ & Jilin & 2.82 & Guizhou & 3.98 \\
\hline Tianjin & 2.57 & Tianjin & 2.48 & Shaanxi & 3.33 & Beijing & 4.12 \\
\hline Jiangxi & 3.82 & Jiangxi & 2.60 & Beijing & 4.12 & Shanxi & 6.15 \\
\hline Beijing & 4.33 & Anhui & 2.88 & Jiangxi & 5.43 & Fujian & 7.33 \\
\hline Anhui & 7.44 & Hubei & 3.25 & Fujian & 5.74 & Liaoning & 7.64 \\
\hline Hunan & 8.08 & Henan & 3.43 & Shanghai & 10.14 & Shanghai & 9.93 \\
\hline Shanghai & 9.93 & Hunan & 3.47 & Anhui & 13.43 & Shaanxi & 10.44 \\
\hline Hubei & 10.31 & Beijing & 4.51 & Hunan & 14.29 & Shandong & 10.76 \\
\hline Fujian & 10.51 & Shanghai & 9.73 & Liaoning & 14.93 & Zhejiang & 11.55 \\
\hline Henan & 10.64 & Liaoning & 10.99 & Guangdong & 15.53 & Jiangsu & 11.92 \\
\hline Liaoning & 12.88 & Fujian & 14.52 & Zhejiang & 15.77 & Hebei & 14.27 \\
\hline Guangdong & 17.03 & Guangdong & 18.38 & Jiangsu & 16.39 & Guangdong & 16.38 \\
\hline Zhejiang & 18.47 & Zhejiang & 20.83 & Shandong & 16.60 & Anhui & 16.66 \\
\hline Hebei & 22.97 & Hebei & 23.15 & Hubei & 19.93 & Hunan & 21.76 \\
\hline Jiangsu & 25.49 & Jiangsu & 34.33 & Henan & 20.35 & Henan & 24.48 \\
\hline Shandong & 26.74 & Shandong & 36.18 & Hebei & 22.76 & Hubei & 30.18 \\
\hline
\end{tabular}

Note : Figures are presented in 1/10000. " ..." stands for the figures inferior to 0.0000005 . For example, a 10 percent increase in the transport network density of Shandong province leads to a $26.74 \times 10^{-4}$ increase of the growth rate of the whole China (except Shandong). Coastal provinces are marked in italics; transport hubs are marked in bold.

The results, shown in tables $3 \mathrm{a}$ and $3 \mathrm{a}$ bis, confirm that the improvement of the transport network in central provinces of Hubei, Henan, and Hunan leads to the most favorable impacts on regional balanced growth. Hence, the ranking of the provinces is not sensitive to the difference in the estimation specifications. 